\title{
A comprehensive numerical simulation of steel-concrete composite beam incorporating compressive failure of concrete
}

\section{$\operatorname{AUTHOR(S):~}$}

Pal, Mahendra Kumar; Yamashita, Takuzo;

Miyamura, Tomoshi; Ohsaki, Makoto

\section{CITATION:}

Pal, Mahendra Kumar ... [et al]. A comprehensive numerical simulation of steel-concrete composite beam incorporating compressive failure of concrete. International Journal of Computational Methods 2019

\section{ISSUE DATE:}

2019

URL:

http://hdl.handle.net/2433/229534

\section{RIGHT:}

This is preprint of an article submitted for consideration in 'International Journal of Computational Methods'.; (c) 2017 copyright World Scienti c Publishing Company (http://www.worldscienti c.com/worldscinet/ijcm). 
This is preprint of an article submitted for consideration in International Journal of Computational Methods.

(C)2017 copyright World Scientific Publishing Company

http://www.worldscientific.com/worldscinet/ijcm.

\title{
A comprehensive numerical simulation of steel-concrete composite beam incorporating compressive failure of concrete
}

\author{
MAHENDRA KUMAR PAL \\ National Research Institute for Earth Science and Disaster Resilience (NIED), \\ Miki, Hyogo, Japan \\ mahendra@bosai.go.jp \\ www.bosai.go.jp/hyogo/research/project/e-sim2008.html \\ TAKUZO YAMASHITA \\ National Research Institute for Earth Science and Disaster Resilience (NIED), \\ Miki, Hyogo, Japan \\ tyamashi@bosai.go.jp \\ TOMOSHI MIYAMURA \\ Department of Computer Science, College of Engineering, Nihon University, \\ Koriyama, Fukushima, Japan \\ miyamura@cs.ce.nihon-u.ac.jp \\ MAKOTO OHSAKI \\ Department of Architecture and Architecture Engineering, Kyoto University, \\ Kyoto, Japan \\ ohsaki@archi.kyoto-u.ac.jp
}

\begin{abstract}
We present a high fidelity numerical simulation technique to analyze the non-linear behavior of a composite beam under cyclic loading. The analysis is performed by using the in-house software called E-Simulator. A constitutive model for concrete; extended Drucker-Prager model considering the compressive failure and the tensile crack has been employed and the parameters are identified so that compressive and tensile behavior of concrete can be reproduced. The relation between the bending moment and deflection angle of a composite beam has been analyzed and compared with experimental results. Damage propagation and stiffness degradation results of concrete slab are demonstrated.
\end{abstract}

Keywords: E-Simulator, Composite Beam, Finite Element Method, Solid Element, Drucker-Prager Model, Compressive Failure.

\section{Introduction}

Three-dimensional full-scale earthquake testing is essential and highly demanded core facility to understand the damage/collapse mechanism of structure and its 
resilience against a seismic wave; in particular, such a large-scale testing facility is necessary for disaster mitigation-based research. Upon assessing this need, National Research Institute for Earth Science and Disaster Resilience (NIED) in Japan constructed a core facility for full-scale earthquake testing at Hyogo Earthquake Engineering Research Center, known as E-Defense [Ohtani et al. (2004); E-Defense (2016)]. E-Defense houses the world's largest shaking table of dimensions $20 \mathrm{~m} \times 15 \mathrm{~m}$, with a payload capacity of 1,200 metric ton. This facility is capable of handling the maximum acceleration of $900 \mathrm{~cm} / \mathrm{s}^{2}$ and $1,500 \mathrm{~cm} / \mathrm{s}^{2}$ in horizontal and vertical directions, respectively.

E-Simulator [Hori et al. (2007)] is a high-performance parallel computing tool developed by and at E-Defense, to accurately simulate the damage/collapse mechanism of civil structures exposed to any sort of earthquake wave. The E-Simulator is incorporated with advanced constitutive material models and failure models for various materials. It uses a general purpose parallel finite element (FE)-analysis software: ADVENTURECluster [Allied Engineering (2016)], as a platform to carry out large-scale numerical computations. The verification and validation of numerical simulation results of E-Simulator are always accomplished mainly by utilizing the experimental results of shake table tests at E-Defense. The reliability of E-Simulator is thus ensured. A sufficiently fine mesh is required to obtain the precise solution and to capture the local behavior. A model with millions of degrees of freedom(DoFs) is, therefore, requested. E-Simulator can handle the analysis with 74 millions of DoFs [Ohsaki et al. (2009)], which is difficult to be achieved by widely used commercial software.

Recent development of seismic response analysis of structures are evidently reported in book [Yoshimura et al. (2016)]. Recently, in simulation of reinforced concrete structures, particle discretization scheme-FEM (PDS-FEM) [Hori et al. (2005); Wijerathane et al. (2009)] has been used to model the fracture phenomena.

A cyclic loading test of a composite beam [Yamada et al. (2009)] was conducted for blind analysis contest of E-Defense shake table test of four-story steel frame structure [Ohsaki et al. (2008)]. This experiment is the target problem for this study. Local buckling of a beam flange was one of the major observation during the experiment.

In this paper, a modification to the extended Drucker-Prager model is proposed by incorporating the compressive failure by introducing a damage variable. A simulation approach for modeling a composite beam i.e. steel beams with a concrete slab under a cyclic loading is demonstrated. A parametric study by using FE analysis of one brick element is performed to determine the material parameters of concrete, and by comparing the obtained simulation result with material test data. It has been demonstrated that by incorporating the compressive failure model the softening behavior of concrete can be reproduced with reasonable accuracy. The relation between the bending moment and deflection angle of a composite beam is analyzed and compared with experimental results. 
This paper consists of five sections. Section one outlines the motivation and background of this research. Section two briefly discusses the various aspects of ESimulator project and section three emphasized on the constitutive models employed for reproducing concrete and steel materials of the composite beam. In section four, experiment and numerical settings of the target specimen are briefly explained. Discussions of numerical simulation results are included in the following section. Finally, the article is concluded and summarized in the last section.

\section{E-Simulator Project}

E-Simulator, which is also referred to as numerical shake table test tool at E-Defense is briefly explained in this section. Verification and validation of E-Simulator are also discussed.

\subsection{Overview}

ADVENTURECluster, which provides the main core of E-Simulator, is an extension of open-source ADVENTURE system. Domain decomposition method is inherent in these tools in the linear algebraic solver and in a parallel implementation. ESimulator has adopted the hierarchical domain decomposition method (HDDM) [Yagawa et al. (1993)]. In HDDM, two level of domain decomposition is performed. At first, a mesh is divided into parts and then these parts are further subdivided into sub-parts called subdomain. Thus, E-Simulator can easily perform the large-scale simulations. E-Simulator is equipped with coarse grid conjugate gradient (CGCG) method; an iterative method with coarse grid corrections, originally developed by Suzuki et al. (2002) and Akiba et al. (2010).

Essential and necessary functions for general purpose finite element code are included into the ADVENTURECluster/E-Simulator. Incorporation of multi-point constraints (MPCs)[Miyamura et al. (2007)] is challenging task in CGCG, for large-scale simulation in particular, and it has been successfully implemented in ADVENTURECluster/E-Simulator. The Hilber-Hughes-Taylor time integration scheme commonly known as $\alpha$-method is incorporated. Non-linear constitutive models and various failure criterion for concrete, steel, rubber, soil and other materials used in civil and building structures are also available. A schematic diagram explaining the step-by-step simulation procedure of E-Simulator is demonstrated in Figure 1.

\subsection{Verification and Validation}

Verification and validation are inherent steps of crucial importance in the software development system. Moreover, it is the accountability of the developing team to estimate the quality of software. E-Simulator project is not different. It is verified and validated at various stages of simulation. It mainly uses the experiment data of shake table test conducted at E-Defense for validation. For a comparative study of 


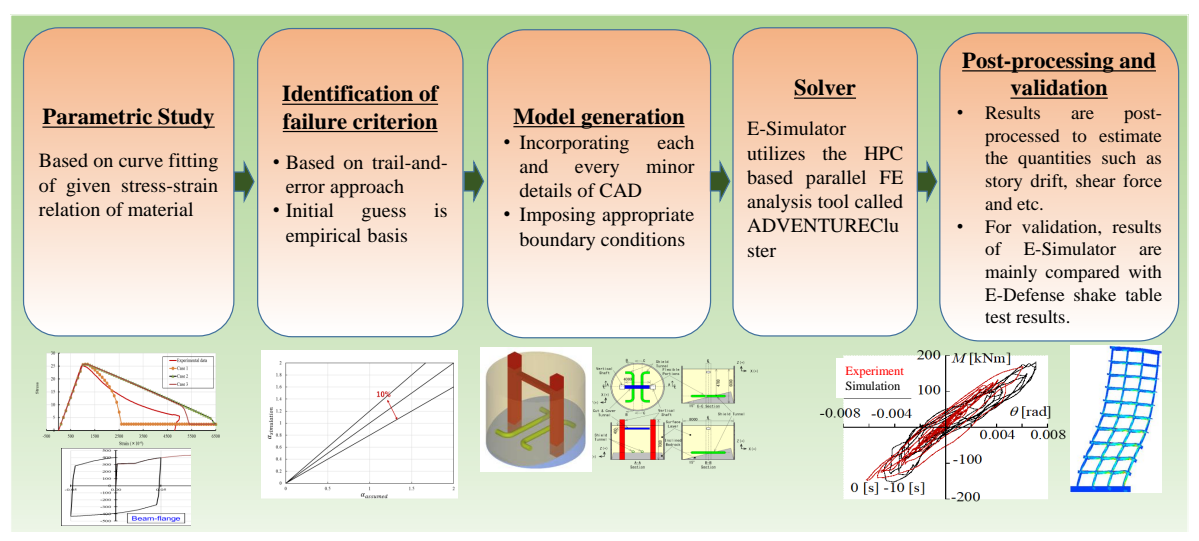

Fig. 1. A schematic illustration of E-Simulator project.

simulation and experiment results at structure-level quantities such as story drift and story shear force, at member-level quantities such as section force and deflection angle, and material-level quantity such as strain are compared. Previous works [Yamashita et al. (2014); Miyamura et al. (2014); Tagawa et al. (2016); Ohsaki et al. (2011)] demonstrate the validation of E-Simulator.

In addition to comparison with experimental results, E-Simulator's results are also verified by comparing with results obtained from other simulation software such as adaptively shifted integration Gauss (ASI-Gauss) technique [Isobe et al. (2013)]. ASI-Gauss technique is an improved version of ASI technique proposed by Toi and Isobe $(1993 ; 1996)$ and it can be used as a computationally faster seismic response analysis tool for frame structures.

\section{Constitutive Model}

In this section, material models for steel and concrete used in this study are briefly discussed. Identification of parameters for concrete constitutive relation is carried out.

\subsection{Steel}

A heuristic and implicit rule, originally developed by Ohsaki et al. (2016) is employed, which is equipped with a piecewise linear isotropic-kinematic hardening law, to reproduce the complex cyclic behavior of steel. Yield plateau and Bauschinger effect are also incorporated in the model. Material parameters and hardening coefficients are determined by using heuristic optimization algorithm, which is documented in the reference [Ohsaki et al. (2016)]. Material parameters of steel are identified through curve fitting with cyclic test results reported by Yamada et al. 
(2002). In the present work, material parameters for steel grades are same as that used in the work of Yamashita et al. (2014). Table 1 shows the initial yield stress of various grades of steel used in different components of the beam. The values of Young's modulus, Poisson's ratio, and mass density are same for all steel and are set to the values of $205 \mathrm{kN} / \mathrm{mm}^{2}, 0.3$ and $7.89 \times 10^{-6} \mathrm{Kg} / \mathrm{mm}^{3}$, respectively. Ratios of isotropic hardening to kinematic hardening $\left(C_{I}^{1}, C_{I}^{2}, C_{I}^{3}\right)$ of steel are tabulated in Table 2, where $\bar{\varepsilon}^{p}$ is equivalent plastic strain. See the Ohsaki et al. (2016) for detailed definitions of parameters.

Table 1. Initial yield stress of steel used in diffeernt componenets of composite beam.

\begin{tabular}{cccc}
\hline $\begin{array}{c}\text { Flange } \\
\left(\mathrm{N} / \mathrm{mm}^{2}\right)\end{array}$ & $\begin{array}{c}\text { Web } \\
\left(\mathrm{N} / \mathrm{mm}^{2}\right)\end{array}$ & $\begin{array}{c}\text { Column } \\
\left(\mathrm{N} / \mathrm{mm}^{2}\right)\end{array}$ & $\begin{array}{c}\text { Diaphragm } \\
\left(\mathrm{N} / \mathrm{mm}^{2}\right)\end{array}$ \\
\hline 319.54 & 366.54 & 325.54 & 315.54 \\
\hline
\end{tabular}

Table 2. Coefficients of isotropic hardening of steel.

\begin{tabular}{cccc}
\hline$C_{I}^{1}$ & $C_{I}^{1}$ & $C_{I}^{2}$ & $C_{I}^{3}$ \\
$\left(\bar{\varepsilon}^{p} \leq 3.15 \times 10^{-5}\right)$ & $\left(\bar{\varepsilon}^{p} \geq 3.15 \times 10^{-5}\right)$ & & \\
\hline-16.5 & 0.67 & 0.0 & 0.67 \\
\hline
\end{tabular}

\subsection{Concrete}

The extended Drucker-Prager (DP) model, which is widely used for the concrete constitutive material model has been implemented. In this work, we propose the modification of the extended DP model by incorporating the compressive failure [Tagawa et al. (2016)] of concrete.

\subsubsection{Extended Drucker-Prager Model considering compressive failure and tensile crack}

The yield surface of the extended Drucker-Prager model is expressed as follows:

$$
\begin{array}{r}
F=\sqrt{l_{F}^{2}+\bar{\sigma}^{2}}-p \tan \phi-d^{\prime} \\
l_{F}=\varepsilon_{F} \sigma_{0}^{y} \tan \phi .
\end{array}
$$

Here, $\bar{\sigma}$ is effective stress, $p$ is hydrostatic pressure and $\sigma_{0}^{y}$ is initial yield stress. $\varepsilon_{F}$ is material constant, $\phi$ is friction angle and $d^{\prime}$ is dependent upon the type of failure 
assumed in the analysis. The parameter $d^{\prime}$ is defined as shown in Eq. (3).

$$
d^{\prime}= \begin{cases}\sqrt{l_{F}^{2}+\left(\sigma^{y}\right)^{2}}-\frac{\sigma^{y}}{3} \tan \phi & \text { for compressive failure } \\ \sqrt{l_{F}^{2}+\left(\sigma^{y}\right)^{2}}+\frac{\sigma^{y}}{3} \tan \phi & \text { for tensile failure } \\ \sqrt{l_{F}^{2}+\left(\sigma^{y}\right)^{2}} & \text { for shear failure }\end{cases}
$$

Here, $\sigma^{y}$ is yield stress in corresponding failure type.

In order to incorporate the compressive failure of concrete, a variable $f_{\text {cave }}$, which is a linear function of equivalent plastic strain, is introduced. The variable $f_{\text {cave }}$ is a quantitative measurement of degradation of the element density and $\left(1-f_{\text {cave }}\right)$ is multiplied as a reduction factor to elastic modulus as is expressed in Eq. (4). The reduction factor $\left(1-f_{\text {cave }}\right)$ is also multiplied to yield stress and hardening parameters.

$$
\boldsymbol{\sigma}=\left(1-f_{\text {cave }}\right) \boldsymbol{D}: \boldsymbol{\epsilon}
$$

Here, $\boldsymbol{\sigma}$ denotes stress tensor, $\boldsymbol{D}$ denotes elasticity tensor and $\boldsymbol{\epsilon}$ denotes elastic strain tensor.

The variable $f_{\text {cave }}$ is defined empirically and formulated using the parameters $e_{0}$ and $e_{1}$ as expressed in Eq. (5). The parameters $e_{0}$ and $e_{1}$ are material parameter.

$$
f_{\text {cave }}= \begin{cases}0.0 & \text { if } \bar{\varepsilon}^{p}<e_{0} \\ f_{\text {cave }}^{\max } \frac{\bar{\varepsilon}^{p}-e_{0}}{e_{1}-e_{0}} & \text { if } e_{0} \leq \bar{\varepsilon}^{p} \leq e_{1} \\ f_{\text {cave }}^{\text {max }} & \text { if } \bar{\varepsilon}^{p}>e_{1}\end{cases}
$$

While, the value of $f_{\text {cave }}$ ranges from 0.0 to 1.0 , one can control the maximum value by declaring $f_{\text {cave }}^{\max }$. Note that the condition $f_{\text {cave }}^{\max } \leq 1.0$ must be satisfied. Figure 2 demonstrates the variation of $f_{\text {cave }}$ with respect to equivalent plastic strain $\bar{\varepsilon}^{p}$.

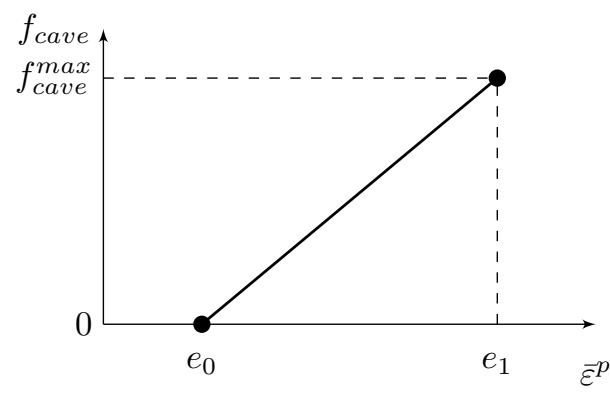

Fig. 2. Variation of variable $f_{\text {cave }}$. 
Tensile cracking of concrete is modeled by decreasing stress to a tolerance value $0.001 \mathrm{~N} / \mathrm{mm}^{2}$, when maximum principle stress exceeds crack stress $2.18 \mathrm{~N} / \mathrm{mm}^{2}$.

\subsubsection{Identification of parameters}

Material properties of concrete shown in Table 3 are determined from the material test. The parameters for the extended DP shown in Table 4 are identified by curve fitting of extended DP yield surface ensuring that it passes through the points corresponding to tensile strength and compressive strength. Equation (3) in compressive failure state is used to evaluate the value of parameter $d^{\prime}$ and value of parameter $d^{\prime}$ is $24.36 \mathrm{~N} / \mathrm{mm}^{2}$. The friction angle of concrete is equal to $50^{\circ}$.

Table 3. Material properties of concrete.

\begin{tabular}{|c|c|c|c|c|}
\hline \multirow{2}{*}{$\begin{array}{l}\text { Young's modulus } \\
\qquad\left(\mathrm{kN} / \mathrm{mm}^{2}\right)\end{array}$} & \multirow[t]{2}{*}{ Poisson's ratio } & \multirow{2}{*}{$\begin{array}{l}\text { Mass density } \\
\left(\mathrm{Kg} / \mathrm{mm}^{3}\right)\end{array}$} & \multicolumn{2}{|c|}{ Strength $\left(\mathrm{N} / \mathrm{mm}^{2}\right)$} \\
\hline & & & Compressive & Tensile \\
\hline 25.61 & 0.2 & $2.3 \times 10^{-6}$ & 25.1 & 2.18 \\
\hline
\end{tabular}

Table 4. Parameters for extended Drucker-Prager model.

\begin{tabular}{cccc}
\hline $\begin{array}{c}\phi \\
(\text { degree })\end{array}$ & $\begin{array}{c}l_{0} \\
\left(\mathrm{~N} / \mathrm{mm}^{2}\right)\end{array}$ & $d_{F}^{\prime}$ \\
\hline 50 & 23.4 & 24.36 & 0.7804 \\
\hline
\end{tabular}

The parameter $e_{1}$ controlling the compressive failure is identified through a parametric study of one brick element as shown in Figure 3 and curve fitting with the material test results. The value of parameter $e_{0}$ is kept constant to 0.0001 . The maximum value of variable $f_{\text {cave }}, f_{\text {cave }}^{\max }$ is set to 0.8 . Essential boundary conditions on nodes of a brick element are tabulated in Table 5 . Negative force or displacement is defined as compression.

The value of parameter $e_{1}$ and hardening coefficients used in this parametric study are listed in Table 6 . The obtained stress-strain relations are demonstrated in Figure 4 . The figure compares the stress-strain curves of numerical simulation with that of the experiment [Ohsaki et al. (2008)]. While Case 1 exhibits sudden damage to concrete, Case 2 exhibits slower damage of concrete. The peak stress point of the concrete constitutive curve in Case 1, 2 and 3 do not match that of the experiment. In Case 4, by adjusting hardening parameters, the peak of the stress-strain curve has a better agreement than Case 3 and softening nature is identical to Case 3. As a result, Case 4 demonstrates the better agreement in comparison with all other 


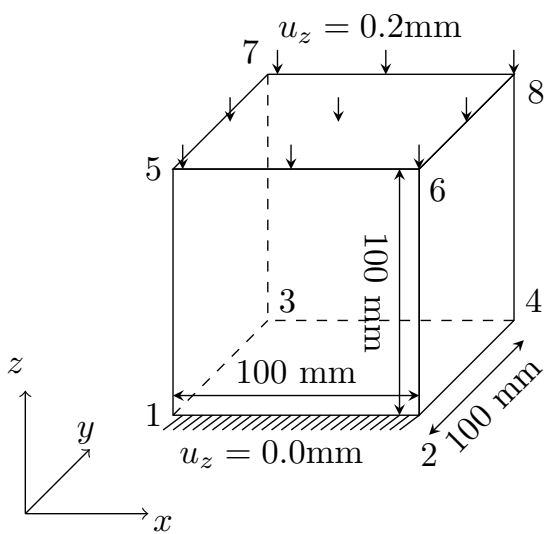

Fig. 3. Problem setting for a parametric study.

Table 5. Essential boundary conditions and applied displcement to various nodes of brick element used for verification problem.

\begin{tabular}{cccc}
\hline Node IDs & \multicolumn{3}{c}{ Applied displacement } \\
& $u_{x}$ & $u_{y}$ & $u_{z}$ \\
\hline 1 & 0 & 0 & 0 \\
$2,3,4$ & - & - & 0 \\
5 & 0 & - & -0.2 \\
$6,7,8$ & - & - & -0.2 \\
\hline
\end{tabular}

Note: Here, empty cell denotes that corresponding DoFs are traction free.

Table 6. Parameters for compressive failure and hardening parameters.

\begin{tabular}{lccc}
\hline Cases & $e_{1}$ table data & \multicolumn{2}{c}{ Hardening $\left(\mathrm{N} / \mathrm{mm}^{2}\right)$} \\
& & $0.0<\bar{\varepsilon}^{p}<1.0$ & $\bar{\varepsilon}^{p} \geq 1.0$ \\
\hline Case 1 & 0.001 & 24.36 & 25.0 \\
Case 2 & 0.005 & 24.36 & 25.0 \\
Case 3 & 0.004 & 24.36 & 25.0 \\
Case 4 & 0.004 & 25.16 & 26.0 \\
\hline
\end{tabular}

cases. Therefore, we decide to use the parameters of Case 4 for the analysis in the next section 


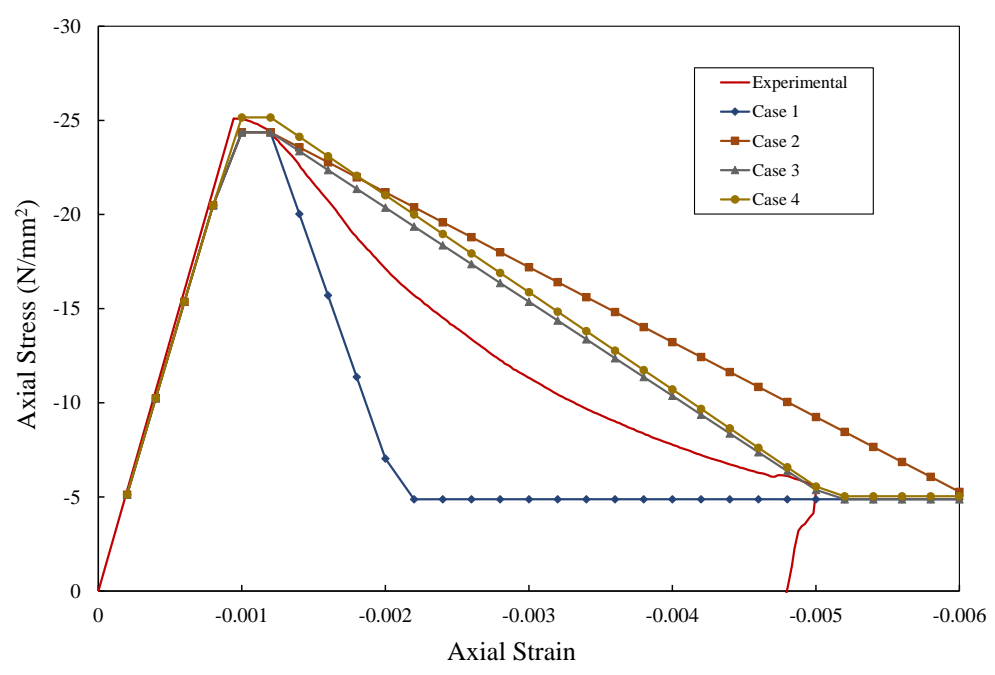

Fig. 4. Stress strain relation of concrete.

\section{Experimental and Numerical Setting}

As a target problem for this study, an experiment performed by Yamada et al. (2009) is simulated. A brief summary of experiment and generated FE-model are presented in this section.

\subsection{Outline of Experiment}

Elevation view drawings of specimen on $z-x$ plane and $y-z$ plane are shown in Figure 5 (a) and (b), respectively. The experimental specimen is comprised of a RHS-300 $\times 9($ BCR295) column, three RH-400×200×8×13 (SN400B) steel beams, a concrete slab, reinforcement bars and stud bolts. A $140 \mathrm{~mm}$ thick concrete slab is made out of M12 concrete-mix. Reinforcement bars (wire-meshes) with diameters of $12 \mathrm{~mm}$ are placed at a uniform spacing of $150 \mathrm{~mm}$ in both directions. These bars are kept at $30 \mathrm{~mm}$ below the top surface of the concrete slab. $110 \mathrm{~mm}$ long stud bolts with diameter of $19 \mathrm{~mm}$ are inserted between the upper flange and concrete slab. Double rows of stud bolts at a spacing of $100 \mathrm{~mm}$ are added along the longitudinal axis of the cantilever beam, while a single row of studs is considered on side beams. The spacing between two consecutive studs is $150 \mathrm{~mm}$ and $160 \mathrm{~mm}$ along the longitudinal axis of side beam and cantilever beam, respectively. Two PL-22 diaphragm plates are also employed in the specimen.

\subsection{Numerical Model}

The generated CAD model of the specimen is discretized for FE-analysis as shown in the Figure 6(c). Except for stud bolts, all other components, namely, beam, 


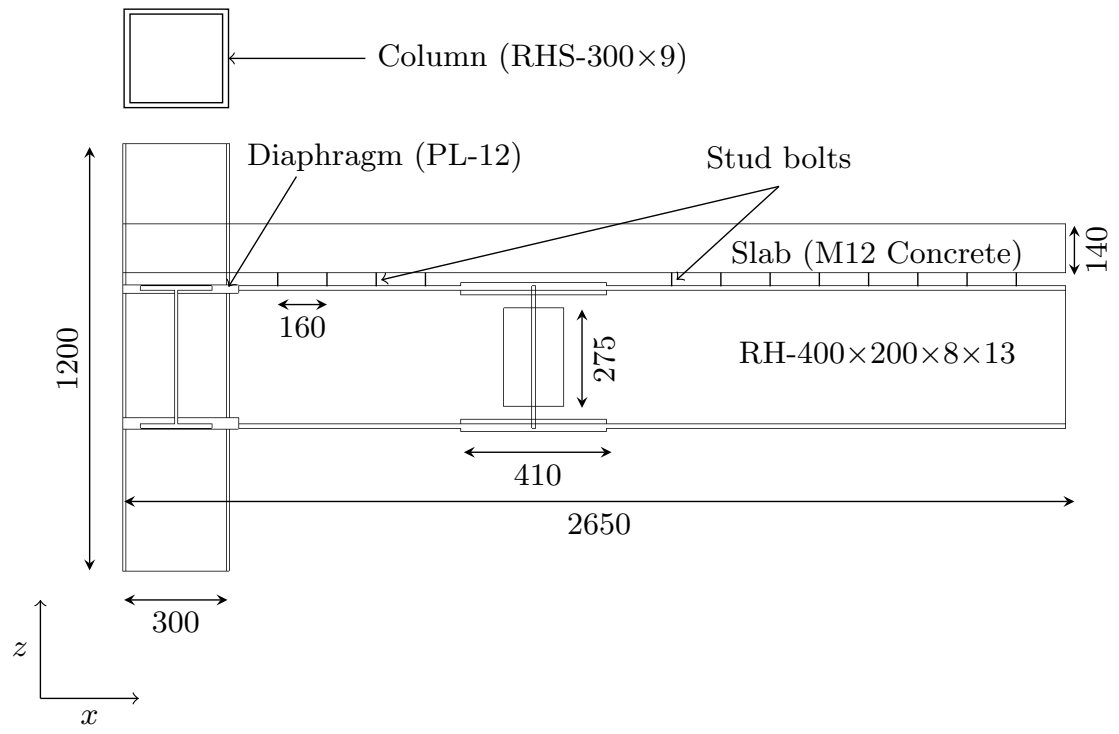

(a) $z-x$ plane

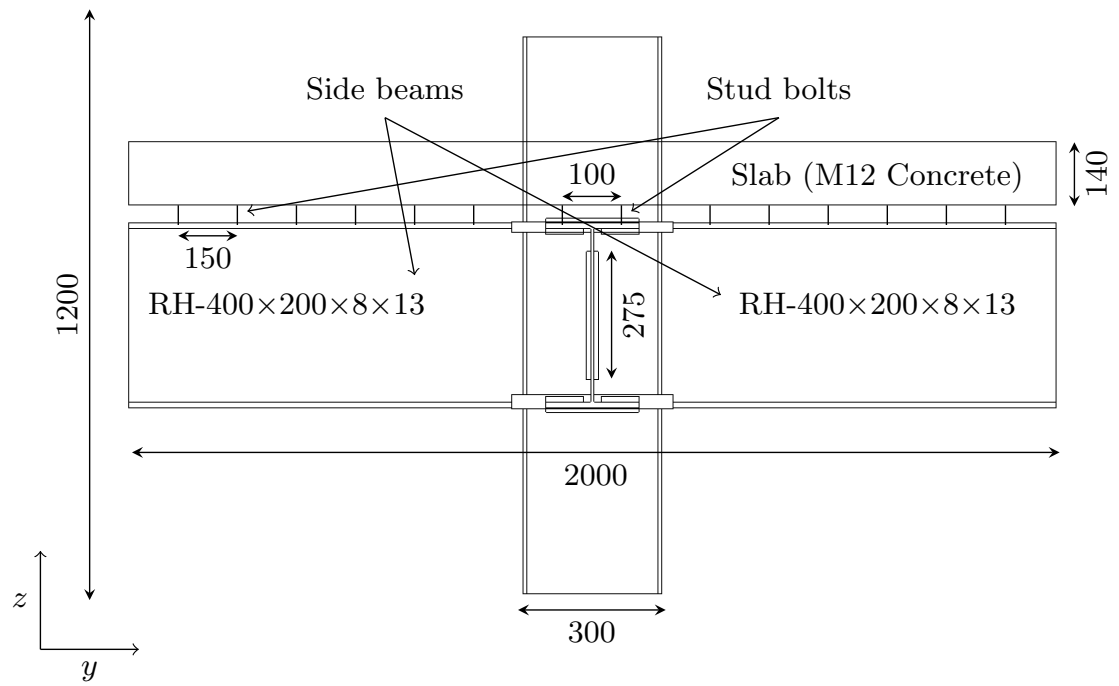

(b) $y-z$ plane

Fig. 5. Elevation view of specimen on (a) $z-x$ (b) $y-z$ plane. All dimensions indicated here are in $\mathrm{mm}$.

column, reinforcement-bar, concrete slab are discretized using linear hexahedral element. Stud bolts are modeled as rigid beam elements as are illustrated in Figure 6 (a) and (b). These rigid beam elements are expanded from middle of concrete to 
top of beam flange. Nodes of these rigid beams at the bottom surface of concrete slab are connected to all immediate neighboring nodes at the bottom surface of the concrete slab as shown in Figure 6(b).

Rigid beam elements are used to impose pin support on the top and bottom section of the column. All nodes on target section are connected to an outside node by the rigid beam elements. Master-slave approach is used to impose contact condition between a column and a slab. While master-nodes are located on the column, slave-nodes are on the slab. Reattachment is considered, but the friction is ignored in the contact modeling. The discretized model comprises of 290,711 nodes, 250,244 linear hexahedral elements, and 3,272 rigid beam elements. Thus total DoFs amounts to 872,133 .

The free end of the cantilever beam is fixed in $y$-direction and constrained for the rotations in $x$ - and $z$-direction. Top and bottom sections of the column are pin supported i.e., rotation in $y$-direction is free and rotations in $x$ - and $z$-directions and all translations are constrained. A cyclic loading is applied as forced displacement in the $z$-direction at the free end of the cantilever beam. The reverse points of loading are controlled using the experimental deflection angles, which are listed in Table 7 in Section 5. In cyclic loading, positive bending implies the upward displacement of the beam and negative bending means downward displacement.

\section{Result and Discussions}

The FE-model demonstrated in Figure 6(c) is analyzed for a cyclic load using ESimulator. As is shown in Figure 7, local buckling observed during the negative bending after the third cycle in the experiment, is successfully simulated. The figure also illustrates damage around the beam-to-column connection. The plastic strain has a concentration in the lower flange due to local buckling, and in the slab due to contact with the column. Figure 8 demonstrates the distribution of equivalent plastic strain in the concrete slab at negative reverse points of the first and fifth cycle of loading. Strain concentration on the concrete slab is observed around the beam-to-column connection and in the neighborhood of stud bolts.

The value of variable $f_{\text {cave }}$ quantifies the extent of damage occurred in concrete. Distribution of variable $f_{\text {cave }}$ in the concrete slab at all reverse points of loading is depicted in Figure 9 (a)-(j). The damage in the region close to beam-to-column connection and in the neighborhood of stud bolts is clearly seen. Furthermore, distributions of equivalent plastic strain (Figure 8(a) and (b)) and that of damage (Figure $9(\mathrm{~b})$ and $(\mathrm{j})$ ) are almost identical. This is obvious because variable $f_{\text {cave }}$ is function of equivalent plastic strain.

The relations between bending moment $M_{b}$ and deflection angle $\theta_{b}$ of composite beam are shown in Figure 10. Both the result of the present simulation and that of the experiment [Yamada et al. (2009)] are shown and compared. Bending moment and deflection angle are calculated as explained in Appendix A. The differences of bending moment and deflection angle between the simulation and the experiment 


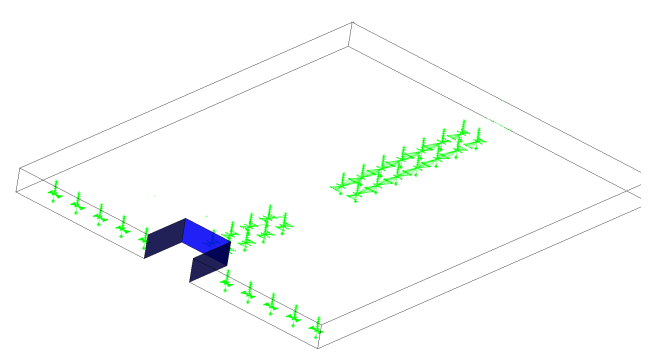

(a) Stud blolts node at center of slab

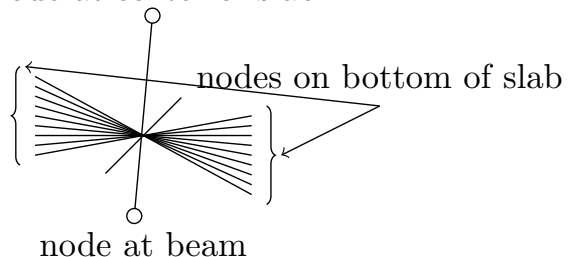

(b) A stud-bolt modelling

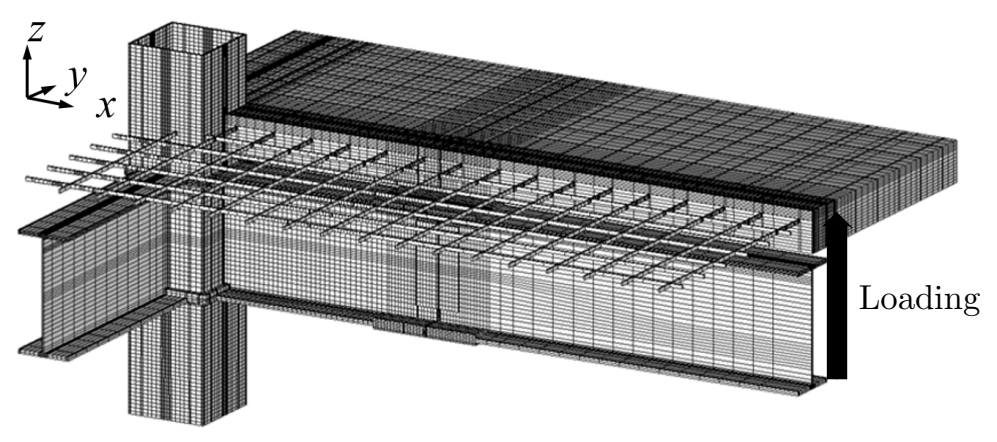

(c) FE analysis model

Fig. 6. Numerical model of specimen.

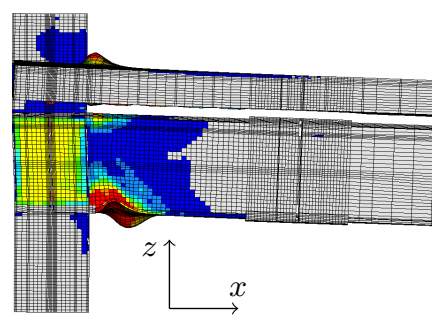

(a) $\theta=-0.031735$

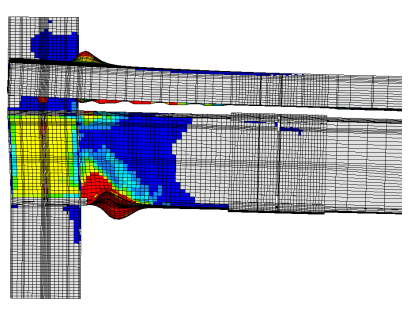

(b) $\theta=-0.0267945$

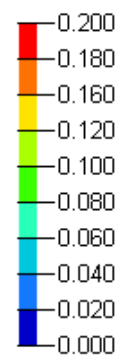

0.000

Fig. 7. Buckling of beam-flange at (a) $\theta_{b}=-0.031735$ of third cycle and (b) $\theta_{b}=-0.0267945$ of fourth cycle; Distribution of equivalent plastic strain.

at reverse points of loadings are listed in Table 7 . Note that as the deflection angles at reverse points are controlled by applying forced displacement on the free end section of the cantilever beam in simulation, a small error less than $5 \%$ to target value is induced.

The initial stiffness of numerical simulation is almost identical to the experi- 


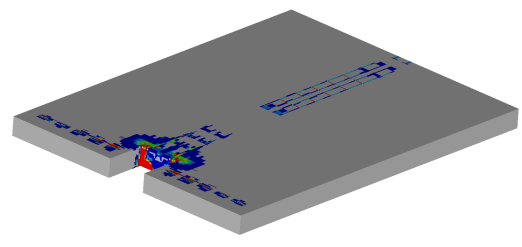

(a) $\theta_{b}=-0.01735852$

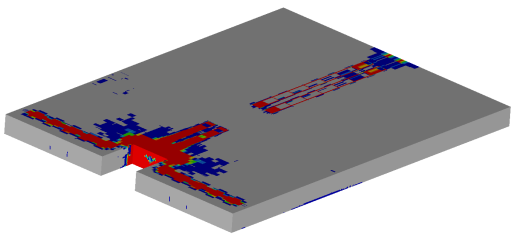

(b) $\theta_{b}=-0.0398365$
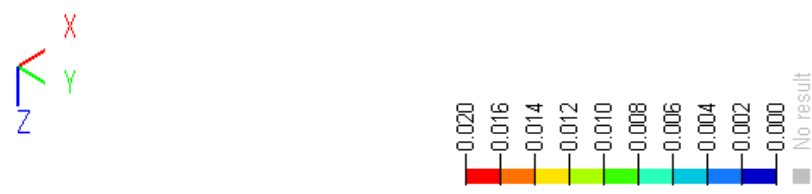

Fig. 8. Distribution of equivalent plastic strain at positive and negative reverse points of first and fifth cycle.

Table 7. Comparison of maximum deflection angle $\theta_{b}$ and beam moment $M_{b}$ at reverse point.

\begin{tabular}{|c|c|c|c|c|c|c|c|}
\hline \multirow{2}{*}{ Cycle } & \multirow{2}{*}{ Reverse Point } & \multicolumn{3}{|c|}{ Deflection angle $\theta_{\text {reverse }}$} & \multicolumn{3}{|c|}{ Beam-moment $M_{b}$} \\
\hline & & Experiment & Simulation & $\%$ Error & Experiment & Simulation & $\%$ Error \\
\hline \multirow{2}{*}{1} & Positive & 0.016954479 & 0.01715274 & 1.17 & 690.86 & 628.81 & 8.98 \\
\hline & Negative & -0.01735852 & -0.01781459 & 2.63 & -451.9257 & -492.90 & 9.06 \\
\hline \multirow{2}{*}{2} & Positive & 0.018401479 & 0.01882855 & 2.32 & 706.96 & 667.02 & 5.65 \\
\hline & Negative & -0.01735952 & -0.01822712 & 4.99 & -465.74 & -492.49 & 5.74 \\
\hline \multirow{2}{*}{3} & Positive & 0.036295479 & 0.03736498 & 2.94 & 753.92 & 778.59 & 3.27 \\
\hline & Negative & -0.03173752 & -0.03069962 & 3.27 & -443.255 & -334.95 & 24.43 \\
\hline \multirow{2}{*}{4} & Positive & 0.029353479 & 0.0305581 & 4.10 & 707.27 & 674.46 & 4.63 \\
\hline & Negative & -0.02679452 & -0.02603373 & 2.84 & -394.94 & -279.69 & 29.18 \\
\hline \multirow{2}{*}{5} & Positive & 0.027294479 & 0.02852906 & 4.52 & 681.94 & 594.84 & 12.77 \\
\hline & Negative & -0.0398365 & -0.03924942 & 1.47 & -336.79 & -222.20 & 34.02 \\
\hline
\end{tabular}

Note: Positive reverse point means loading is changing from positive bending to negative bending. Negative reverse point means loading is changing from negative bending to positive bending.

ment with an error of approximately 3\%. Bending stiffness at all the reverse points has comparatively good agreement. However, stiffness degradation during negative bending differs. In the first and second cycle i.e., before initiation of buckling, maximum bending moment is smaller than that of the experiment at positive reverse points. On the other hand, the maximum bending moment of simulation is larger than that of the experiment at negative reverse points. However, the difference between the maximum bending moment of simulation and experiment is less than $9 \%$. After initiation of buckling in the third cycle from than onwards the difference of maximum bending moment becomes larger than the first and second cycle. Although the maximum bending moment is underestimated, softening behavior during the negative bending after occurrence of buckling, is successfully simulated. 


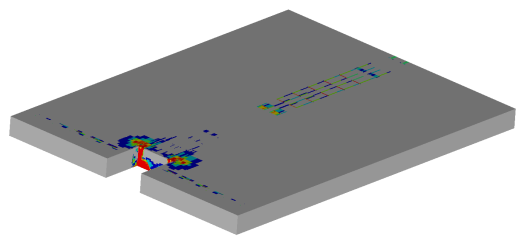

(a) $\theta_{b}=0.016954479$

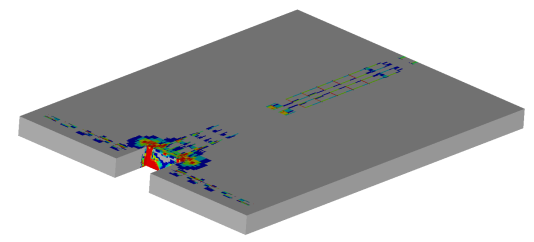

(b) $\theta_{b}=-0.01735852$

First cycle

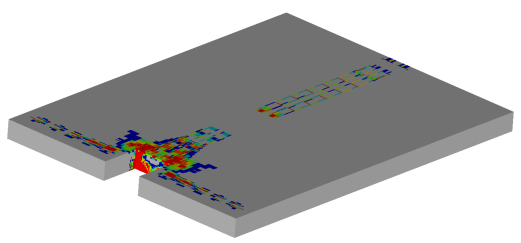

(c) $\theta_{b}=0.0184015$

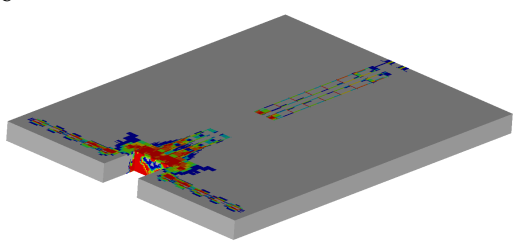

(d) $\theta_{b}=-0.0173595$

Second cycle

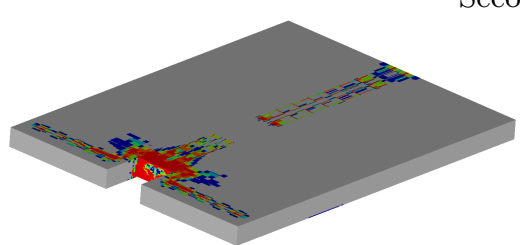

(e) $\theta_{b}=0.0362955$

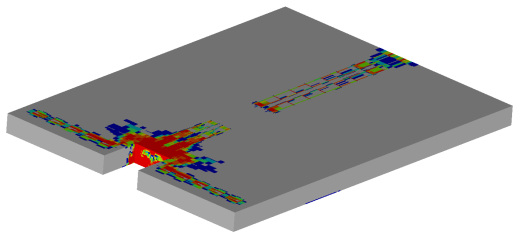

(f) $\theta_{b}=-0.0317375$

Third cycle

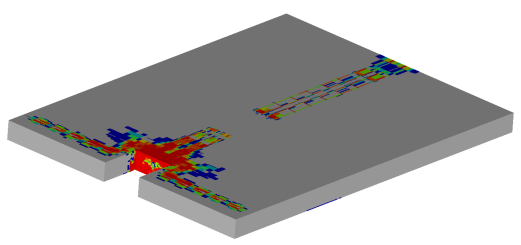

(g) $\theta_{b}=0.0293535$

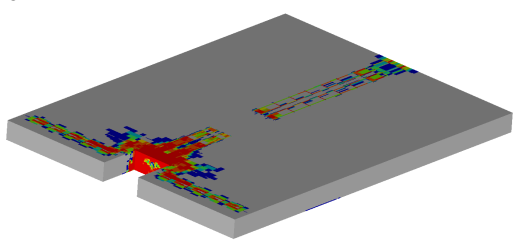

(h) $\theta_{b}=-0.0267945$

Fourth cycle

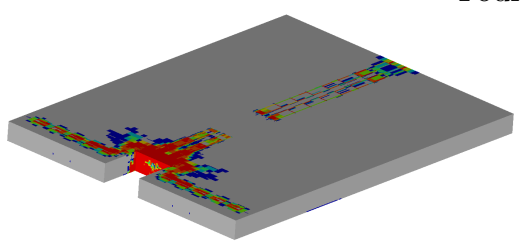

(i) $\theta_{b}=0.0272945$

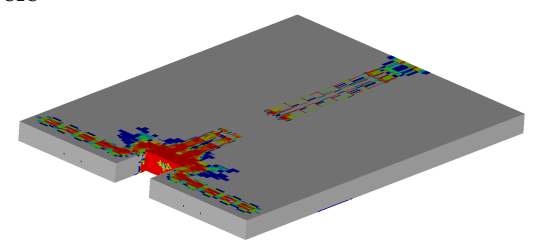

(j) $\theta_{b}=-0.0398365$

Fifth cycle<smiles>[X]C([X])([X])[X]</smiles>

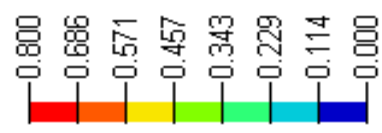

Fig. 9. Propagation of damage in concrete slab at positive and negative reverse points of loading; contours of the variable $f_{\text {cave }}$. 


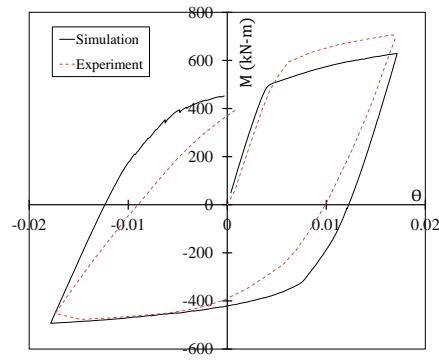

(a) First cycle

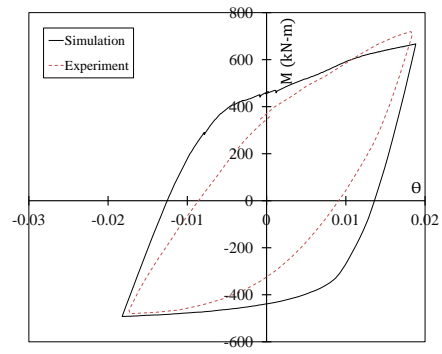

(b) Second cycle

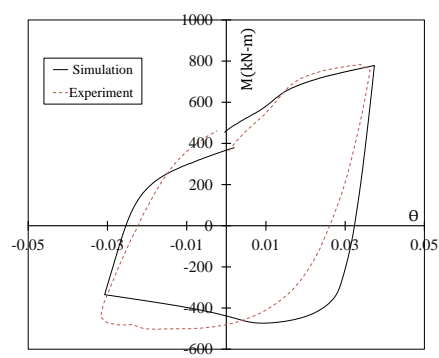

(c) Third cycle

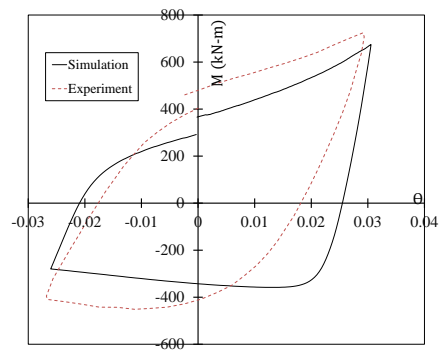

(d) Fourth cycle

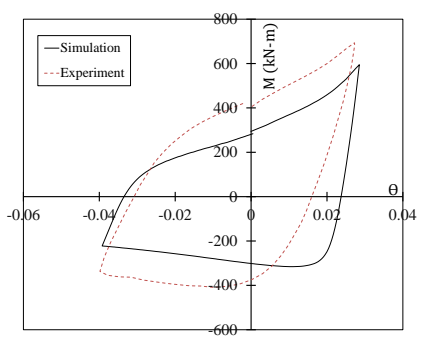

(e) Fifth cycle

Fig. 10. Comparison of beam-moment $M_{b}$ and beam-to-column deflection angle $\theta_{b}$. 
Lower stiffness degradation in the negative bending leads to overestimation of hysteresis damping and different vibration characteristics of structures comprised of composite beam with large deformation. To overcome this problem, improvement of the tensile crack model by considering cyclic behavior is the target future problem.

\section{Summary}

A modification to the extended Drucker-Prager model is proposed and implemented by incorporating the compressive failure by introducing the damage variable $f_{\text {cave }}$. The identification of the material parameters for concrete is accomplished using a parametric study of one brick element by comparing the results with material test data. A high fidelity finite element analysis of a composite beam under cyclic loading is accomplished and simulation results are compared with cyclic test results. The strength is well estimated before the buckling of the beam. After the buckling of the beam, though the strength is underestimated, softening behavior corresponding to buckling during negative bending is successfully simulated. Propagation of damage in concrete slab is also simulated successfully. In order to reproduce the stiffness degradation in the negative process, improvement of the tensile crack model may be necessary.

\section{Acknowledgements}

This research is a part of Architecture Working Group (WG) (Leader: Prof. Tomoshi Miyamura, Nihon University) of E-Simulator Production Committee (Leader: Prof. Makoto Ohsaki, Kyoto University) of NIED. The authors acknowledge the valuable contribution from committee members, and the financial support by NIED. Authors wish to express their sincere thanks to Dr. Jun Fujiwara of NIED for his kind assistance in the simulation.

\section{References}

Akiba, H (2010). Large Scale drop impact analysis of mobile phone using ADVC on Blue GENE/L In proceedings of International conference on high performance computing networking and storage (SC06) Tampa USA .

Allied Engineering Corporation, http://www.alde.co.jp/english/advc/index.html, as of $2016 / 10 / 20$.

ASME .(2006). Guide for verification and validation in computational solid mechanics.

E-Defense, http://www.bosai.go.jp/hyogo/ehyogo/, as of 2016/10/20.

Hori, M., Noguchi H. and Ine T. (2007). Project report of development of numerical shaking table coping with E-Defense. Journal of Earthquake Engineering (JSCE), 29: 14201425 (In Japanese).

Hori, M., Oguni, K. and Sakaguchi, H.(2005). Proposal of FEM implemented with particle discretization scheme for analysis of failure phenomena, J. of Mech. and Phys. of Solids, 53 pp. 681-703.

Isobe, D., Han, W. S. and Miyamura, T. (2013). Verification and validation of seismic response analysis code for framed structure using ASI-Gauss technique. Earthquake Engineering and Structural Dynamics, 42: 1767-1784. 
Miyamura, T. (2007). Incorporation of Multipoint constraints into Balancing Domain Decomposition Method and its parallel implementation International Journal for numerical method in engineering, 69: 326-346.

Miyamura, T., Yamashita, T., Akiba, H. and Ohsaki, M. (2014). Dynamic FE analysis of four-story steel frame modeled by solid elements and its validation using results of full-scale shake-table test Earthquake Engineering and Structural dynamics, DOI:10.1002/eqe.2526.

Ohsaki, M., Kasai, K., Matsuoka, Y. and Zhang, JY. (2008). Results of recent E-Defense tests on full-scale steel building:part 2, collapse simulation and blind analysis contest. In proceedings of the Structures Congress 2008 ASCE, Vancouver.

Ohsaki, M., Miyamura, T., Kohiyama, M., Hori, M., Noguchi, H., Akiba, H., Kajiwara, K. and Ine, T. (2009). High-precision finite element analysis of elastoplastic dynamic responses of super-highrise steel frames. Earthquake Engineering and Structural dynamics, 38(5): 635-654.

Ohsaki, M., Miyamura, T., Kohiyama, M., Zhang, JY., Isobe, D., Onda, D., Yamashita, T., Hori, M., Akiba, H. and Kajiwara, K. (2011). High-precision FE analysis for collapse simulation of steel frames considering composite beam effect. EUROSTEEL 2011, (CDROM).

Ohsaki, M., Miyamura, T. and Zhang, JY (2016). A piecewise linear isotropic-kinematic hardening model with semi-implicit rules for cyclic loading and its parameter identification Computer Modeling and Engineering, 111(4): 303-333.

Ohtani, K., Ogawa, N., Katayama, T. and Shibata, H. (2004). Construction of E-Defense (3-D Full-scale Earthquake Testing Facility) In proceeding of the 13th World Conference on Earthquake Engineering, Vancouver, B.C. Canada.

Suzuki, M., Ohayam, T., Akiba, H., Yoshimura, S., and Noguchi, H. (2002). Development of fast and robust parallel CGCG solver for large scale finite element analyses transactions of Japan Society of Mechanical Engineering, A68: 1010-1017 (In Japanese).

Tagawa,H., Ohsaki, M., Yamashita, T., Miyamura, T. and Kohiyama, M. (2016). Detailed finite element analysis of concrete-filled-tube using E-simulator implemented with extended Drucker Prager constitutive law considering tension crack and compression damage In proceedings of the conference on computational Engineering and Science, 21: May, 2016. (In Japanese).

Toi, Y. and Isobe, D. (1993). Adaptive shifted integration technique for finite element collapse analysis of framed structures. International Journal for Numerical Method in Engineering, 36: 2323-2339.

Toi, Y. and Isobe, D. (1996). Finite element analysis of quasi-static and dynamic collapse behaviors of framed structures by adaptive shifted integration technique. Computers and Structures 58(5): 947-955.

Wijerathne, M.L.L. , Oguni, K., Hori, M.(2009). Numerical analysis of growing crack problem using particle discretization scheme, Int. J. for Numerical Methods in Engineering, 80 pp. $46-73$.

Yagawa, G. and Shioya, R.(1993) Parallel Finite Elements on a massively parallel computer with domain decomposition, Computing Systems in Engineering, 4: 495-503.

Yamada, S., Imaeda, T., and Okada, K. (2002). Simple hysteresis model of structural steel considering the Bauschinger effect. Journal of Construction Engineering, 559: 225-232 (In Japanese).

Yamada, S., Satsukawa, K., Kishiki, S., Shimada, Y., Matsuoka, Y. and Suita, K. (2009). Elasto-plastic behaviour of panel zone in beam-to-external column connection with concrete slab. Journal of Structural and Construction Engineering (Transaction of Architectural Inst. of Japan), 74(644): 1841-1849 (In Japanese). 
Yamashita, T., Miyamura, T., Akiba, H. and Kajiwara, K. (2013). Verification of finiteelement elastic-plastic buckling analysis of square steel tube column using solid elements. Transaction of Japan Society of Computational Engineering and Science, Paper No. 20130001 (In Japanese).

Yamashita, T., Ohsaki, M., Kohiyama, M., Miyamura, T., Zhang, J. and Tagawa, H. (2014). Detailed finite element analysis of composite beam under cyclic loading. Journal of Construction Engineering, 79(704): 1481-1490 (In Japanese).

Yoshimura, S., Hori, M. and Ohsaki, M. (Eds.) (2016) Seismic Response Simulation of Building Structures High-Performance Computing for Structural Mechanics and Earthquake/Tsunami Engineering Springer International Publishing,: 105-139.

\section{Appendix A. Calculation of bending moment and deflection angle}

A brief explanation of bending moment $M_{b}$ and deflection angle $\theta_{b}$ calculation methodology [Yamada et al. (2009)] adopted in this study is presented here. Explicit expression are given as followings

$$
\begin{aligned}
M_{b} & =Q L_{b} \\
\theta_{b} & =\left[u_{t}-\left(\theta_{f} L_{b}+u_{c}\right)\right] / L_{b} .
\end{aligned}
$$

Here, $Q$ is the shear force at the free end of a cantilever beam and $L_{b}$ is the total length of the cantilever beam from the column face on the positive side as defined in Figure 11. $\theta_{f}$ is the quantitative measurement of distortion of column cross section (see in the figure 11 ). $u_{t}$ and $u_{c}$ are total vertical displacement of the beam end and vertical beam shift at positive side of connection due to column distortion from the original position, respectively. The term $\left[u_{t}-\left(\theta_{f} L_{b}+u_{c}\right)\right]$ gives the relative displacement of beam end.

Four corner nodes of each face on the positive and negative side are considered to calculate the $\theta_{f}$. Reaction force at a node on which forced displacement is applied is used as the shear forces $Q$. The total vertical displacement $u_{t}$ is evaluated as average displacement of free-end-of-beam. These computed values of displacements and shear force are then substituted in above-mentioned Eq. (A.1 and A.2 ) to calculate $\theta_{b}$ and $M_{b}$ for each time step. 


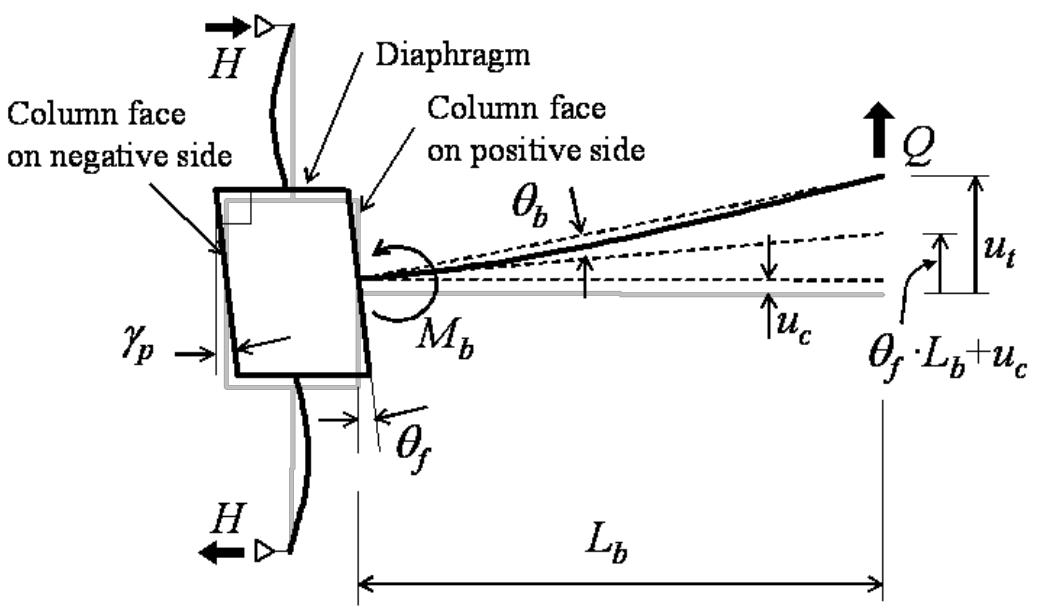

Fig. 11. Definition of beam moment $M_{b}$ and beam-to-column deflection angle $\theta_{b}$ 